\title{
LA CICLOVÍA DE BOGOTÁ: CUARENTA AÑOS DE RECREACIÓN EN LA CIUDAD
}

\author{
BOGOTÁ'S CICLOVÍA: FORTY YEARS OF RECREATION IN THE CITY
}

\section{A CICLOVIA DE BOGOTÁ: QUARENTA ANOS DE RECREAÇÃO NA CIDADE}

\author{
Astrid Bibiana Rodríguez Cortés ${ }^{1}$
}

\section{Resumen}

Este artículo presenta los hallazgos de la primera etapa de la investigación en curso "El dispositivo del espacio público la Ciclovía de Bogotá como productor de subjetividades". Este documento plantea el contexto de la investigación (desde 1970 al presente), sus principales referentes conceptuales (la producción de subjetividad como fabricación y el espacio público como espacio de poder y gobernanza) y un análisis de la masa documental (revisión del periódico El Tiempo entre 1970 y 2013, y entrevistas a usuarios, directores y promotores de la Ciclovía). Se establece al espacio público como dispositivo usado como medio para ejemplificar y gestionar formas de vivir. Asimismo, se evidencian las tres líneas discursivas que prevalecen en la configuración histórica de este espacio público recreativo.

Palabras clave: espacio público; subjetividad; ciclovía

Abstract

This article is intended to present the findings of the first stage of an ongoing research titled "The device of public space: Bogotá's Ciclovía as a producer of subjectivities." This document presents the context of the research (1970 to present), its main conceptual references (the production of subjectivity as fabrication and public space as a space of power and governance), and an analysis of the review of issues of El Tiempo between the years 1970 and 2013, as well as interviews with users, directors and promoters of the Ciclovía. Public space is established as a device used to exemplify and manage ways of living. We also shed some light on the three main discursive lines in the history of this public recreational space.

Keywords: public space; subjectivity; Ciclovía

\section{Resumo}

Este artigo apresenta as descobertas do primeiro estágio da pesquisa em curso "O dispositivo do espaço público da Ciclovia de Bogotá como produtor de subjetividades". Este documento apresenta o contexto da pesquisa (desde 1970 até hoje), seus principais referentes conceptuais (a produção de subjetividade como fabricação e o espaço público como espaço do poder e governança) e uma análise da massa documental (revisão do periódico El Tiempo entre 1970 e 2013, e entrevistas a usuários, diretores e promotores da Ciclovia). Estabelece-se o espaço público como dispositivo utilizado como meio para exemplificar e gerenciar formas de viver. Assim mesmo, evidenciam-se as três linhas discursivas que prevalecem na configuração histórica deste espaço público recreativo.

Palavras chave: espaço público; subjetividade; ciclovia

Fecha de recepción: 24 de mayo de 2016

Fecha de aprobación: 5 de noviembre de 2016

Para citar este artículo:

Rodríguez, A. (2007). La Ciclovía de Bogotá: cuarenta años de recreación en la ciudad. Lúdica Pedagógica, (25), 73-82.

1 Candidata a doctor en Estudios Sociales, Universidad Externado de Colombia. Magíster en Educación. Profesora Investigadora de planta de la Facultad de Educación Física de la Universidad Pedagógica Nacional. Correo electrónico: abrodriguez@pedagogica.edu. co,astridbibianarc@gmail.com 


\section{INTRODUCCIÓN}

El presente artículo forma parte de la investigación doctoral en curso "El dispositivo del espacio público, la ciclovía de Bogotá, como productor de subjetividades", la cual busca establecer la relación entre la configuración del espacio público y la producción de subjetividades, centrándose en la ciclovía de la ciudad de Bogotá. El problema de investigación asume una mirada crítica que interpela los saberes, discursos y prácticas que sustentan las políticas públicas que configuran este espacio público urbano y su relación con las formas en que el sujeto las asume. La investigación se encuentra inscrita bajo el modelo teórico-metodológico genealógico-arqueológico, con el que se busca comprender la fabricación de subjetividades en un contexto histórico y social determinado, mediante la evidencia de las relaciones entre saber, poder y sujeto, las cuales normalizan a los individuos y sus conductas en un marco de gubernamentalidad.

La investigación cuenta con dos momentos: el primero evidencia las líneas de fuerza que configuran el dispositivo, entendido como redes que se establecen entre discursos y prácticas "que busca determinar las formas de ser, hacer y conocer del sujeto en un momento histórico determinado, constituyéndose en acontecimiento, de tal modo que se afirma que el dispositivo es un modo de construir subjetividad"(Martínez, 2013, p. 81). El segundo momento tiene que ver con evidenciar las formas de resistencia, las maneras éticas en que los individuos se asumen en este espacio, las prácticas de libertad que se ejercen. Por tanto, este trabajo se propone mostrar tanto las relaciones de poder que se disponen en la configuración de este espacio público -la ciclovía-; en palabras de Foucault (2006), se trata de hacer una ontología del presente, una comprensión de cómo nos construimos y de generar una actitud crítica sobre nosotros mismos.

El propósito de este artículo es dar cuenta de los hallazgos del primer momento de la investigación. En este se establecen las líneas discursivas que configuran el dispositivo de la ciclovía, espacio público de recreación, y su relación con la producción de subjetividades.

\section{CONTEXTO}

Con relación al problema de los espacios, Michel Foucault (2010) ha realizado un trabajo amplio. Para este autor, hacer una historia de los espacios es esencialmente hacer una historia de los poderes, esta perspectiva pone en consideración estrategias de organización y arquitectura que disponen los espacios en una red de relaciones de saber/poder, así en sus diferentes trabajos en la cárcel, el hospital, la escuela, evidenció las tácticas que se mueven para hacer de la organización espacial un dispositivo de control social. Para él, la arquitectura a partir del siglo xviII empieza hacer una reflexión sobre lo que debe ser el orden de una sociedad en la ciudad, evitando las enfermedades y contagios, la convivencia familiar y conjunta, llevando así a crear una política que regule el urbanismo, los equipamientos colectivos, la higiene y la arquitectura privada (Foucault, 2010, p.85). Para Foucault, la época actual es la del espacio, el cual instituye un campo de relaciones sociales, en donde se efectúan una serie de operaciones sobre los cuerpos de los hombres.

La configuración del espacio público es vista también como una tensión entre la institucionalidad y los sujetos que lo ocupan, lo cual hace que su producción sea un campo de fuerzas, donde la comunidad busca formas para apropiarse de él, quizás como una manera de resistirse a la acción de nuevos ordenes capitalistas; asimismo, la institucionalidad plantea normas para reglamentar su planificación, uso y aprovechamiento. Como ejemplo de ello, se cita, el domingo 16 de diciembre del año 1974 en Bogotá, donde se produce el "Mitin a favor de la cicla”, promovido por una organización social llamada Procicla. Este tenía como fin empoderar a los ciudadanos a salir con su bicicleta y tomarse las principales calles de Bogotá, en resistencia a la llegada masiva de carros, transporte urbano y contaminación ambiental. Esta práctica se volvió relativamente usual. Algunos domingos, ciudadanos bogotanos empezaron a tomarse las calles de la ciudad con su bicicleta, tanto como un acto de protesta, como de empoderamiento del espacio público, así como una forma de recreación masiva (Palacios, 1974).

Entre 1974 y 1994, esta toma de la ciudad por parte de los bogotanos se hizo de manera intermitente, dependió en algunos momentos de los alcaldes de turno y de la viabilidad que permitieran entidades como Tránsito y Transporte. Sin embargo, en 1995, retomando las iniciativas populares, se da inicio por parte del Instituto Distrital de Recreación y Deporte (IDRD) de Bogotá, a la Ciclovía, un programa de recreación, el cual decidió que algunas de las vías se convertirían en un espacio público de recreación masiva, espacio para ejercitarse, territorio 
de exploración corporal y diversión. Las prácticas de ejercitación corporal modificaron el sentido de las calles que inicialmente fueron construidas para el tránsito y el transporte. Sin embargo, los domingos y días feriados en las calles bogotanas emergerían nuevas metáforas y sentidos sociales.

En 1995, inicialmente mediante una evaluación de su estado y retomando los $24 \mathrm{~km}$ entregados al IDRD, se determina el objetivo de su trabajo en: "Hacer unos circuitos organizados y estructurados con sentido de uso. Desde esa época la administración se centra en un objetivo 'formar ciudad'” (Alcaldía Mayor de Bogotá, 2007, p. 124).

Desde 1996 hasta 1998, el IDRD tomó la decisión de transformar el programa ciclovía. Algunos de los grandes cambios que enfrentó el programa fueron: amplitud de sus recorridos de 24 a $81 \mathrm{~km}$, la conexión con los parques donde existía la recreovía (clases de actividad física), la ampliación del horario de funcionamiento, además se conformó un equipo interinstitucional (bachilleres auxiliares, funcionario de la secretaria de salud y de tránsito y transporte, guardianes y gerentes de ciclovía) todos ellos cuidando y brindando seguridad. Estos cambios fueron generando una masiva campaña de apropiación del espacio público por parte de los ciudadanos. Años más adelante el programa lanza un famoso slogan: "Bogotá no tiene mar pero tiene ciclovía", que será recordado entre los bogotanos. Se implementó un servicio de comunicación por radio y se contó así con el primer patrocinador de la ciclovía: Agua Brisa (Alcaldía Mayor de Bogotá, 2007). En 1998 se empieza a dar más institucionalidad al grupo humano que conforma el espacio: se crean los puestos para mascotas, se realiza un plan para vendedores ambulantes, se generan múltiples campañas pedagógicas y entra Suramericana como patrocinador, se amplía el sistema de comunicación radio y buscapersonas.

Actualmente, todos los domingos y días festivos en Bogotá, desde las 7:00 a.m. hasta las 2:00 p.m. el IDRD cierra algunas de las avenidas principales. En total, son 121 kilómetros de Ciclovía que son usados para la práctica de actividad física, recreación y esparcimiento de los bogotanos. Este espacio se concibe como público, normalmente regulado por las políticas de la Alcaldía Mayor de Bogotá, bajo la dirección del IDRD.

\section{Ejes conceptuales}

\section{La producción de subjetividad como fabricación}

Recientemente los estudios sobre subjetividad han sido prolíficos, parten de disciplinas como psicología, sociología, filosofía e historia. Esta investigación recurre a una mirada interdisciplinar, siguiendo lo planteado por Foucault (1996), se puede comprender la subjetividad como producto y resultado de un ejercicio del poder/ saber y verdad bajo ciertas condiciones de posibilidad histórica y económica. Interesa a este trabajo comprender dos aspectos, por un lado, cómo los sujetos asumen verdades en sus vidas, las constituyen e instauran en modos de comportamiento, estilos y formas de gestionar y administrar su vida, y por otro, cómo ejercen resistencia en su cotidianidad a estas lógicas de podersaber que de una forma u otra los configura. Esta idea de producción de subjetividad permite comprender, como lo explican Guattari y Rolnik (2006), la modelización que se hace de los comportamientos, la sensibilidad, la percepción, la memoria, las relaciones sociales, en este caso, en los espacios públicos.

Sin embargo, la producción de subjetividades no es vista solo como una sujeción, sino que también tiene en cuenta la formación individual, la experiencia y el sentido vivido del sujeto, donde están implícitas hoy las dimensiones del deseo, "en donde los seres humanos no son sujeto de un régimen coherente de gobierno, que produce personas tal como las sueña. Por el contrario, los hombres viven sus vidas moviéndose constantemente en distintas prácticas que los subjetivan de modo distinto" (Rose, 1996, p. 17).

Será De Certeau, en La invención de lo cotidiano (1999) quien precisamente planteará claves para comprender cómo las prácticas cotidianas de los sujetos son altamente creativas, evidenciando nuevas formas de moverse frente al poder. Los procedimientos de esa creatividad cotidiana sorprenden y sobrepasan, en algún momento, las técnicas investigativas que intentan comprender la lógica de su producción. Se tratará más bien, en palabras de De Certeau (1999), de retomar lo que es un arte como manera de hacer, para él estas prácticas ponen en juego una ratio popular, "una manera de pensar investida de una manera de actuar" (p. XLV). Esta perspectiva de la creatividad cotidiana del sujeto se entenderá aquí como un acto de libertad, que para Foucault (2001)“es la condición ontológica de la ética. Pero la ética es la forma de reflexión que adquiere la 
libertad" (p.396). Por tanto, de lo que se trata es de problematizar esta libertad, esta capacidad de optar con la que se cuenta, ya que ella es precisamente la que permite establecer una relación de constitución del sí mismo como sujeto libre, entablando maneras de relacionarse consigo mismo más desde la construcción que desde la determinación, más desde la ética y la estética de la existencia que desde la dominación, es decir, concebir la vida como arte, generando subjetividades autónomas, creadoras, que ejercen luchas distintas.

\section{El espacio público como espacio de poder y gobernanza}

Tal como lo presenta Martínez (2014), hacer una genealogía de la categoría de espacio público es evidenciar "una forma espacial inaugurada por unas relaciones de poder que quieren 'dar el lugar apropiado' a ciertas interacciones humanas, en el marco de un modelo gubernamental específico, históricamente rastreable que pretende dirigir la vida" (p.44). Esta perspectiva de análisis evidencia la necesidad de preguntarse por cómo se ha configurado hoy la noción de espacio público, y cuáles son las relaciones de poder que sustentan su configuración, en un marco de gubernamentabilidad.

Hoy se comprende a los espacios públicos de recreación como lugares específicos y apropiados para el descanso, la tranquilidad, la convivencia pacífica y el bienestar social, asimismo, son diseñados para la sociabilidad y esparcimiento de los sujetos llevando a encuentros personales de placidez y confort. Se enumeran entre otros: plazas, parques, playas. Para esta investigación se contemplará la ciclovía como espacio público constituido para tal fin.

Estos espacios se configuran como redes donde se entrecruzan líneas de fuerzas, como: acciones morales de comportamiento, normas institucionales, saberes, planeaciones y disposiciones arquitectónicas, que disponen a los sujetos para que actúen, piensen y se asuman de determinada manera. El entrecruzamiento de dichas líneas de fuerzas lleva a que en este estudio se plantee a los espacios públicos como dispositivos, siguiendo lo propuesto por Agamben (2011): "El dispositivo es antes que todo una máquina que produce subjetivaciones y por ello también es una máquina de gobierno" (p. 261), es decir, la ciclovía como espacio público es un escenario donde se proponen técnicas que pretenden dirigir la forma como los sujetos deben percibirse, su disposición espacial y las maneras de gobernar las conductas de los llamados usuarios, instaurando modelos de ciudadanía, estereotipos de cuerpos saludables y prácticas de actividad física.

\section{METODOLOGÍA}

Estableciéndose como método la arqueología del saber y la genealogía del poder, la primera se ocupa de rastrear la producción de discursos en una formación histórica [..] y la segunda se ocupa de estudiar y analizar el ejercicio y la resistencia al poder, de rastrear la producción de discursos en una formación histórica, entendiendo por ella "los umbrales de saber, muy diversos entre sí que se constituyeron en una época". (Deleuze, 2013, p. 33).

Por ello, de lo que se trataría con la arqueología del saber y la genealogía del poder es evidenciar los procesos de visibilidad y los procederes de enunciabilidad de una época. Estos dos aspectos, lo visible y lo enunciable,son los que Foucault reconocerá como saber, jugándose desde allí el problema de la verdad, los cuales atraviesan la producción de subjetividades. Para Foucault "no hay nada bajo el saber" (citado por Deleuze,2013,p. 33). Así, su diferencia con la historia está dada en la medida que genealogía y arqueología desvanecen la idea de origen y linealidad. En tal sentido, lo explica Martínez (2010):

Quien trate de construir esta historia de las relaciones entre sujeto, verdad y poder deberá ficcionalizarlas; es decir, asumir un marco empírico como soporte analítico, pero evitar suponer una perspectiva causal o lineal de los eventos históricos. [...] Se trata de anular la visión de un sujeto universal que vive y narra la Historia, para considerar acontecimientos discontinuos con conexiones que se evidencian en transformaciones constatables en empiricidades discursivas (documentos como monumento, archivo) y relaciones de poder que funcionan como efectos de dispositivos y técnicas puestas en marcha. (pp. 76-77).

Asumir esta perspectiva metodológica implica rastrear los discursos que han hecho posibles los regímenes de verdad que constituyen subjetividades en un momento histórico determinado, "lo cual implica principalmente que las épocas, las formaciones históricas no ven lo mismo, no dicen lo mismo. Las visibilidades y los enunciados son las variables de cada formación". (Deleuze, 2013, p. 36). 
Por tanto, implica rastrear las prácticas discursivas, en este caso, sobre las cuales se ha construido el saber sobre el espacio público de la ciclovía de Bogotá. No se trata de hacer una historia lineal donde se busque el origen en sí mismo, sino más bien las condiciones de posibilidad de los discursos que han permitido la emergencia y el surgimiento de este evento. Lo que se indaga son las construcciones y redes que se entretejen entre las instituciones que sostienen un proyecto como este, establecer los focos de poder, sus discursos y las líneas de fuerzas que propician un dispositivo del espacio público que produce subjetividades.

\section{FUENTES}

Dosson los tipos de fuente sobre los cuales se basa la investigación:

1. Revisión periódico El Tiempo en un periodo comprendido entre1970 y 2013.

2. Entrevistas ausuarios, directores y promotores de la ciclovía.

La primera parte de la investigación se centró en la lectura y análisis de la revisión de fuentes primarias del periódico El Tiempo, escogido por ser el diario de mayor circulación en el país. En ese sentido, lo que aquí se presenta son los resultados de esta primera fase.

\section{PROCEDIMIENTO}

La arqueología se centra en la construcción de archivos, lo cual significa definir la formación histórica, es decir, el entrecruzamiento entre lo visible, lo enunciable de una época histórica, extrayendo de allí los enunciados. Una vez identificados los enunciados, se forma un corpus, el cual está dado por un conjunto finito de palabras, frases y proposiciones efectivamente dichas y usadas en la época (Deleuze, 2013,p. 68). La identificación de este conjunto finito permitirá encontrar las regularidades y las reglas de formación y constitución del corpus seleccionado. Esto determinará los enunciados donde se pueden ubicar las relaciones de poder/saber.

Teniendo en cuenta lo anterior se construye el archivo, con los siguientes pasos:

- Ubicación de las fuentes primarias: la revisión se realiza en el periódico El Tiempo, los meses de enero, junio y diciembre desde 1970 hasta 2014. La selección de los artículos se hace teniendo en cuenta las siguientes palabras clave: espacio público, ciudad, ciclovía, transporte, movilidad y bicicleta.

- Lectura temática: una vez localizados los documentos, se orienta un primer momento de lectura, el cual dará cuenta de: primero, las fuentes reales de trabajo y segundo, de las temáticas, palabras y frases emergentes.

- Lectura contextual: consiste en situar los textos en momentos históricos y caracterizar hechos sociales en los que se encuentran inmersas las fuentes.

- Extracción y selección de los enunciados: regularidades y discontinuidades delas palabras y discursos. Esto constituye el régimen de enunciados, es decir, la manera como se hace repetible en la materialidad empírica.

- Escritura con perspectiva crítica: evidencia el funcionamiento ideológico de los discursos sobre el espacio público, los mecanismos de apropiación, por parte de algunas instituciones, así como la construcción de los discursos económicos y sociales, y las formas de subjetivación.

Puede decirse que la búsqueda de información tiene tres grandes momentos de lectura: uno, la ubicación general de las fuentes; otro, el análisis y la emergencia de grandes relaciones, y por último, la configuración de los enunciados teniendo en cuenta las regularidades y discontinuidades.

\section{Resultados}

En total, se hizo una revisión de 2700 periódicos físicos entre 1970 y 2007. Desde 2008 hasta 2014 se consultaron los artículos digitalizados por el periódico $E l$ Tiempo, manteniendo el patrón de los meses establecidos. Finalizado este proceso de revisión, se realizó una nueva búsqueda teniendo en cuenta los filtros que ofrecen las bases de datos del diario, de lo que se obtuvieron algunos artículos que no correspondían a los meses inicialmente seleccionados. La muestra total se configura con 1025 artículos, relacionados en la figura 1.

Teniendo en cuenta el objeto de la investigación, se realizó un segundo filtro, seleccionando los artículos que 
guardan relación directa con la ciclovía; como resultado, se encontraron 195 artículos.

\section{Características de los artículos seleccionados}

Los 195 artículos seleccionados se organizaron y agruparon por recurrencias: bicicletas, ciclorrutas, ciudad, ciudadanía, espacio público, recreación, recreovíaciclovía, salud-actividad física (figura 3).

\section{Discusión}

Las formas de organización, los discursos que se instituyen como verdades y las prácticas sociales que se ejecutan en la ciclovía como espacio público, se interpelan aquí. La producción de este espacio público -que se dice ser cada vez más amable, saludable y humano a la luz de las políticas de actividad física, acciones y discursos gubernamentales-, diseña y configura, en palabras de Castro-Gómez (citando a Foucault), la producción de espacios como una técnica orientada al gobierno de las poblaciones (2010, p.69). El despliegue de técnicas, prácticas y discursos que promueven este tipo de racionalidad sobre la forma en que se diseñan los lugares, así como lo que se pone en marcha sobre él, permite a los individuos plantearse otras formas de relacionarse con los espacios, con ellos mismos y con sus cuerpos. Esta racionalidad gubernamental alimenta aspiraciones de libertad, bienestar y deseo de consumo reflejado, para este caso, en salud y belleza corporal.

Se puede, entonces, agregar que la materialidad empírica de los enunciados encontrados en el análisis de las fuentes documentales presentan tres características importantes: a) las líneas discursivas más preponderantes, b) la transformación de los enunciados en términos históricos, c) la configuración de un espacio público como la ciclovía produce una subjetividad de autorresponsabilidad por una vida sana y ejercitada.

\section{Líneas discursivas preponderantes}

En el análisis de la construcción del archivo, la repetitividad enunciativa permitió dar cuenta de tres líneas discursivas: primero, los discursos que ven que el espacio de la ciclovía es determinante para contribuir a un modelo de cultura y educación ciudadana. Segundo, discursos que insisten en cómo las prácticas que se ejecutan en este espacio crean una conciencia sobre la necesidad de la actividad física y la salud de los ciudadanos como una manera de cuidar su cuerpo, manteniendo cuerpos saludables, atléticos y estéticamente cuidados. El tercer grupo de discursos tiene que ver con la contribución de la bicicleta al cuidado ambiental. Si bien la ciclovía retoma otras prácticas físicas como caminar, patinar, correr, se persiste en la bicicleta como artefacto que contribuye al mejoramiento ambiental.

Se considera así que el entramado de fuerzas y líneas de fuga que maneja la ciclovía como espacio público, desvela una red de discursos: de carácter ambiental, salud y educación ciudadana, que contempla un tejido de prácticas discursivas y no discursivas, que constituye una máquina de subjetivación que gobierna y conduce a los sujetos; es decir, productora y producto de espacios, cuerpos y subjetividades.

\section{Transformación de los enunciados en términos históricos}

Una de los aspectos interesantes es cómo el dispositivo empieza a construirse con el paso del tiempo; es decir, la ciclovía en su forma original, tenía unos fines diferentes a los que hoy están instaurados. Lo que inicialmente pretendía el "Mitin a favor de la cicla" en 1974 era abogar por la construcción de carriles específicos para la movilidad de la bicicleta; sin embargo, tomarse las calles de la ciudad como una forma de protesta, se convirtió, décadas después, en un escenario público de disfrute social de los habitantes.

Varios discursos sufren mutaciones con el paso del tiempo, entre ellos: en la década de 1970, mayoritariamente aparece en las fotografías de los periódicos la figura masculina. La bicicleta que era un artefacto que se asociaba con la fuerza y rudeza, del ciclista como deportista de la época, del campesino que la usaba en la zona rural o de los trabajadores que optaban por este medio por ser más económico para transportarse. Sin embargo, finalizando esa década, la comercialización de bicicletas, especialmente la marca Monark, introduce en el mercado modelos femeninos y juveniles, haciendo de este artefacto un objeto recreativo. Estos cambios comerciales fueron importantes para que las mujeres y los niños se hicieran visibles en el espacio de la ciclovía (Montezuma, 2011).

Sin embargo, con el pasar de las décadas, la presencia de la mujer empieza a ser determinante. Hacia finales de los años ochenta, las fotografías de mujeres con trajes deportivos ajustados son las que más se van a publicitar. En los años 1990,las fotografías se centran 


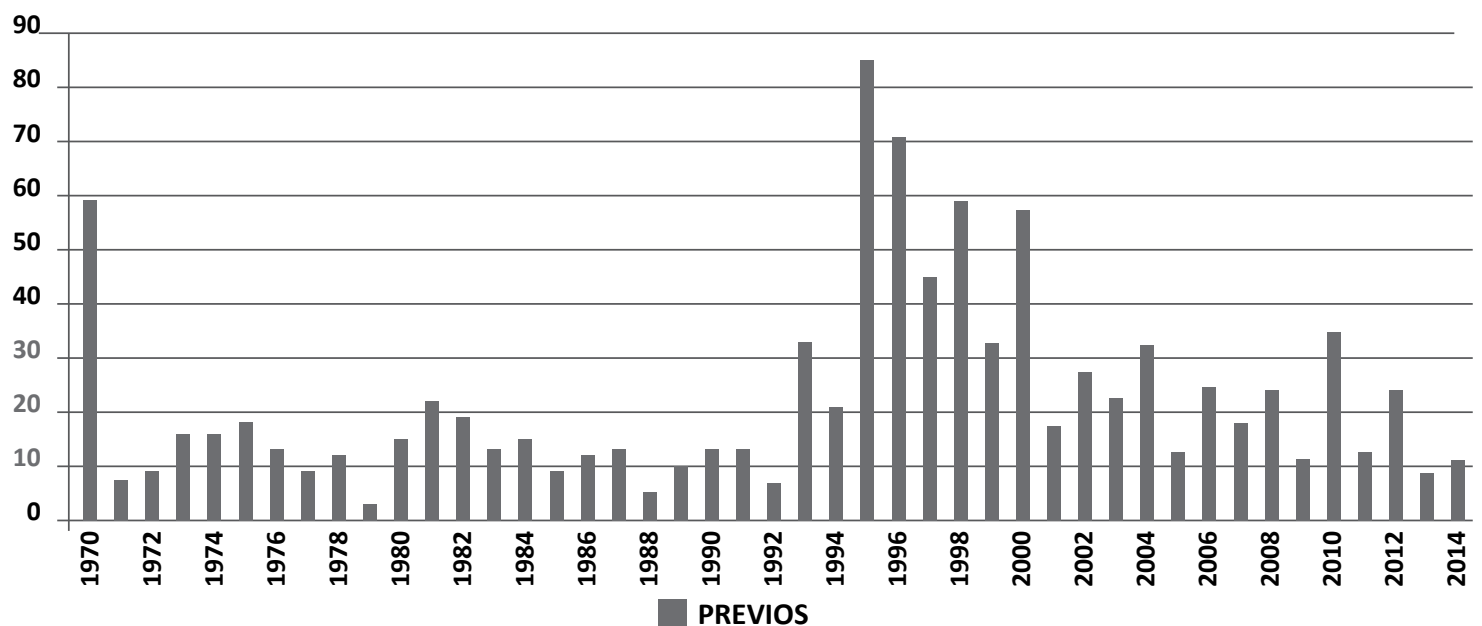

Figura 1. Relación de cantidad de artículos por año Fuente: elaboración propia

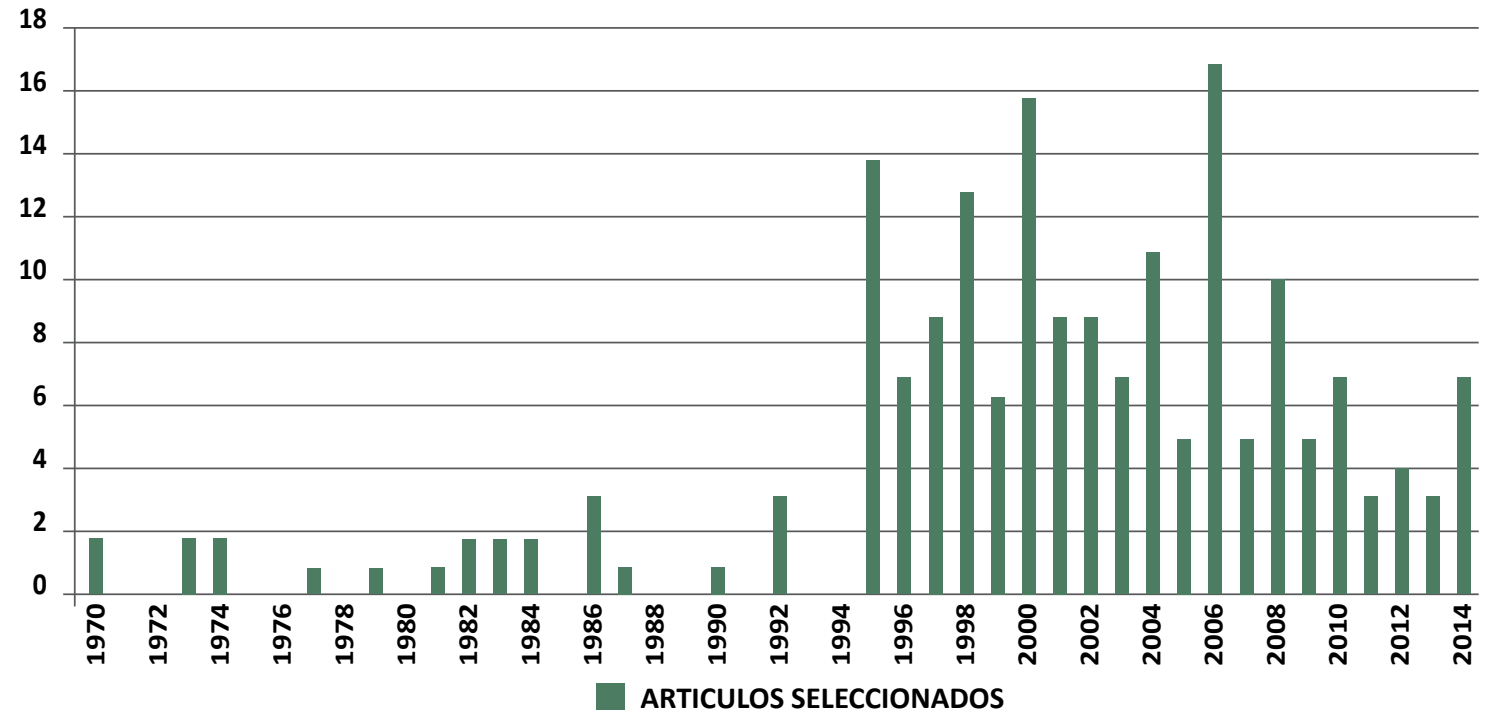

Figura 2.Número de artículos seleccionados por año Fuente: elaboración propia

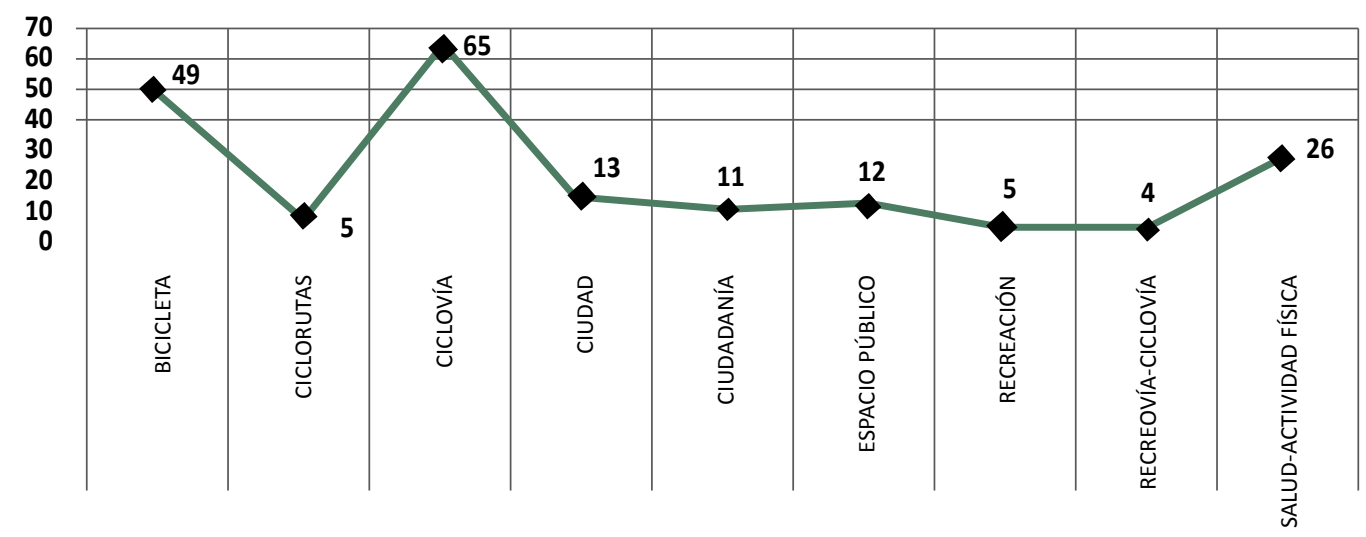

CONFORMACIÓN MASA DOCUMENTAL-FUENTE EL TIEMPO

Figura 3.Número de artículos por recurrencia Fuente: elaboración propia 
en los hombres y mujeres con cuerpos estéticamente agradables, exaltando los colores variados de los trajes deportivos y la belleza del escenario en el que se convertía la ciclovía para la ciudad. En el nuevo siglo, la publicidad se enfoca en una ciclovía incluyente, que se dispone para la familia y su mascota, un ambiente que promueve la integración social y familiar.

Otro discurso que se transforma es el uso de la bicicleta. Los artículos de prensa en los años setenta, asociaban la bicicleta con las personas de menos ingresos económicos o con los ciclistas, deportistas que se presentan como sujetos sufridos que con gran empuje logran representar al país. Décadas después la bicicleta deja de ser un artículo deportivo y su uso se hace recreativo, simultáneamente la bicicleta toma fuerza como objeto de movilidad, pujando fuertemente por la construcción de vías específicas para su tránsito, las cuales se reconocerán como ciclorrutas. Así, ya no solo era el trabajador de escasos recursos quien debía usarla, ni los niños y las mujeres a nivel recreativo. La bicicleta en la ciudad empezó a ocupar un lugar distinto, la promoción de los diferentes alcaldes, demostrando ellos mismos su uso, representando cómo los ejecutivos también podían llegar en bicicleta a su trabajo, desplegó una serie de campañas que promocionaron un estilo propio y sofisticado de usar la bicicleta. Así, de aquella publicidad del campesino que usaba la bicicleta de los años 1970, se pasa a "Mi estilo es bici", nombre de la campaña que se impulsa desde 2013, para promover su uso. Esta iniciativa se enfoca en mostrar cómo distintas personas, especialmente de clase alta, pueden hacer uso de la bicicleta, generando una idea de inclusión y equidad social, todos podemos formar parte de "Mi estilo es bici".

En tanto, los discursos de actividad física surgen principalmente a finales de la década de 1990 Asociados a políticas de salud y estadísticas que develaban el aumento de la obesidad en la población, la cual develaba el aumento de la obesidad en la población. Este discurso fue incrementándose vertiginosamente, se instauraron retos de actividad física que incentivaban a que las personas se movieran en distintos países a determinadas horas, estableciendo récords mundiales. Campañas de salud en el espacio público de la ciclovía empiezan a surgir.
Lo más relevante de este cambio fue pasar de enfermedad no transmisible a epidemia y por último a estilo de vida saludable, focalizando su mirada sobre los sujetos en sobrepeso. El obeso empieza a ser objeto de intervención. La ciclovía, como escenario de exhibición corporal, empieza a hacer notar con mayor atención la cantidad de personas que podrían estar en riesgo o están en sobrepeso. Por tanto, la mejor manera de combatir esta epidemia es ejercitarse, hacer actividad física, alimentarse adecuadamente. Por tanto, la ciclovía adopta medidas para controlar el tipo de alimentación que se vende, la cual debe estar dentro de los regímenes de comida sana; así mismo, se reparten folletos y campañas en los que se recomienda sobre cómo tener un estilo de vida sano, entre ellos están: las formas de comer, rutinas de ejercicio y maneras adecuadas de vivir, cruzadas con las que se espera promover ciudadanos y ciudades saludables.

\section{La ciclovía, productora de subjetividades}

Uno de los hallazgos interesantes para esta investigación es comprender cómo el espacio público sigue siendo usado para instaurar estereotipos de gestionar el deseo y la vida contemporánea de los ciudadanos. En el caso de la ciclovía bogotana, pensada como espacio de recreación y ejercitación, se asume el ejercicio físico como una práctica sobre sí mismo, que mejora la capacidad física y productiva, que acondiciona y relaja para asumir la carga laboral de la semana, así como los discursos sobre las enfermedades no transmisibles, entre ellas, la obesidad, hacen de la ejercitación contemporánea un técnica de subjetivación.

Peter Sloterdijk (2012), desde el concepto de antropotécnicas, evidencia cómo los procedimientos de ejercitación, físicos y mentales con los que los hombres de las culturas más dispares han intentado optimizar su estado inmunológico, frente a los riesgos de la vida (p. 24). Para Sloterdijk, si el siglo XIX estuvo centrado en lo cognitivo y el siglo xx en la reflexividad, el futuro estará enfocado en el ejercicio físico (p. 17). Este autor presenta cómo las prácticas corporizadas generan en la sociedad expresiones convencionales de educación, usos, costumbres, conformación de hábitos, entrenamientos, ejercicios; es a través de la práctica física que el cuerpo se educa, modela y acondiciona creando hábitos y modificando la relación consigo mismo. 
Por ello, "un dios será una especie de atleta", enuncia Sloterdijk, su cuerpo que se impone frente a los mortales, será un camino a seguir, en él se nota el esfuerzo, pero también la perseverancia, la disciplina y el vitalismo, erigiéndose como ejemplo, como modelo orientador. Por ello, esta manera de instaurar esa visibilidad sobre el cuerpo genera formas de subjetivar, de hacer del otro ese modelo a seguir, siendo esto uno de los aspectos más importantes de la ciclovía de Bogotá como espacio público.

Con el surgimiento de la personalidad en la edad moderna, Sloterdijk ve nacer el sujeto mirabile, el sujeto que tiene que hacer de su vida un escenario y vivir en un performance tanto interior como exterior, está apreciación es fundamental para este trabajo, pues se concibe aquí la ciclovía como una gran pasarela de la ciudad, un escenario de exposición, donde los sujetos se muestran, pero así mismo observan, como una forma de configuración social. Se asiste, a las maneras en que el sujeto moderno se modela así mismo, donde se establece como sujeto de admiración a partir de estereotipos y gestión de su propio yo, como proyecto de empresa.

En este mismo sentido, el espacio público urbano se articula y forma parte de esta sociedad del espectáculo, la ciudad se convierte en un escenario de disfrute social, tal como lo diría Verdú (2003):

En el capitalismo de producción, las ciudades se situaban cerca de los lugares donde abundaban las materias primas para la producción industrial. En el capitalismo de consumo, las ciudades crecieron como centros de comercio y servicios. Ahora, en el capitalismo de ficción sin eludir atributos de otras épocas, la condensación urbana se ofrece como artilugio recreativo o aventurero, dispuesto para el entretenimiento. (p. 41).

Por ello, los ciudadanos buscan divertirse en la ciudad, y la ciclovía se presenta como un escenario perfecto para ello, su forma estructurada y amplia para recorrer la ciudad la ubica como un escenario público de amplias posibilidades. Por tanto, aquí no se quiere en ningún momento negar todos los beneficios que este espacio tiene para la calidad de vida de los bogotanos, pero con una mirada crítica se quiere hacer reconocer cómo este espacio forma parte de las biopolíticas que controlan cómo los sujetos viven su cotidianidad.
Ser buenos ciudadanos hoy pasa por ser sujetos que se cuiden a sí mismo, con prácticas físicas saludables y ambientales, de autorresponsabilidad, es decir, cuidarse implica también cuidar el planeta. Ser un sujeto ecológico hoy implica tener tanto un estilo de vida saludable y ecológico, aquel que se declare amigo de los discursos ecológicos demuestra su amor usando la bicicleta cotidianamente, ya que ello propende por el cuidado físico y respeto ambiental. Así, la ciclovía promueve sujetos ecológicos, saludables y felices, que a partir de su ejercitación semanal hacen que su ciudadanía sea cada vez más activa, que ejercen su derecho al uso de un espacio público que con gran esfuerzo se le ha quitado a los carros y a la modernización voraz de la ciudad.

\section{CONCLUSIONES}

La configuración de un espacio público como la ciclovía de Bogotá se define a como un ejemplo a seguir. La ciclovía ha sido un ejercicio ciudadano activo que, de una forma u otra, ha interpelado el uso del carro como medio de transporte y ascenso social. Este espacio de los domingos y los días de fiesta ha configurado un gran escenario de disfrute colectivo. La ciudad ha sido reconocida en diferentes eventos por la manera en que se gestiona y organiza para promover un estilo de vida sano y ambiental. Sin embargo, lo que aquí se ha intentado mostrar es cómo este espacio público es usado como dispositivo que instaura formas de gestionar la vida de los ciudadanos.

Asimismo, la ciclovía al igual que otros espacios públicos de la ciudad, corren el riesgo de convertirse en escaparates, desde donde se vende la idea de Bogotá como ciudad incluyente, sana y saludable, invisibilizando las carencias y conflictos sociales que aún tiene esta metrópoli en crecimiento. Promover un espacio público estéticamente bonito que permita la venta y competitividad de Bogotá parece ser una de las preocupaciones fuertes de las políticas urbanas desde los años 1990 en la organización de la ciudad.

Por último, este documento destaca cómo el dispositivo se ha venido construyendo a lo largo de cuarenta años; el espacio público de la ciclovía es un espacio vital para la ciudad, por ello, múltiples discursos y prácticas empiezan a surgir, estableciéndose como una red que configura a los sujetos que se preocupan por mantenerse sanos, estéticamente atractivos y ecológicamente activos, 
todo ello en una sociedad contemporánea de ficción y espectáculo que quiere promover cada vez más espacios públicos de diversión y entretenimiento masivo.

\section{REFERENCIAS}

Alcaldía Mayor de Bogotá (2007). La ciclovía: laboratorio para el futuro. Bogotá: Instituto Distrital de Recreación y Deporte.

Agamben, G. (2011). ¿Qué es un dispositivo? Sociológica,73, 249-264.

Castro-Gómez, S. (2010). Historia de la gubernamentalidad. Bogotá: Siglo del Hombre.

El saber. Curso sobre Foucault. Buenos Aires: Cactus.

Foucault, M. (2006). La hermenéutica del sujeto. Buenos Aires: Fondo de cultura económica.

Foucault, M. (2001). El sujeto y el poder. Postscriptum. En: H. Dreyfus y P. Rabinow. Más allá del estructuralismo y la hermenéutica (pp. 241-259). Buenos Aires: Editorial Nueva Visión.

Foucault, M. (1996). Tecnologías del yo. Barcelona: Paidós.

Instituto Distrital de Recreación y Deporte. (s.f.). Historia de la ciclovía en Bogotá. Recuperado el 1 de octubre de 2014, de http://www.inbogota.com/transporte/ ciclovia/historia.htm.

De Certeau , M. (1999). La invención de lo cotidiano. México: Universidad Iberoamericana
Deleuze, G. (2013). El cuerpo utópico las heterotopías. Buenos Aires: Claves

Guattari, F. Rolnik, S. (2006). Micropolítica. Cartografias del deseo. Madrid: Traficantes de Lefebvre, H. (1974/2013). La producción del espacio. Madrid: Capitán Swing.

Martínez, J. (2014). Subjetividad, biopolítica y educación una lectura desde el dispositivo. Bogotá: Unisalle.

Martínez, J. (2010). La universidad productora de productores entre biopolítica y subjetividad. Bogotá: Universidad de la Salle.

Martínez, J. (2013). El dispositivo: una grilla de análisis en la visibilización de las subjetividades. Tabula Rasa, 19, 79-99.

Montezuma, R.(2011).Ciudadanos, calles y ciudades: las Américas unidas por una ciclovía. Bogotá: Fundación Ciudad Humana.

Palacios, R. (16 de diciembre de 1974). Mitin en favor de la cicla. Periódico El Tiempo, p.6A.

Rose, N. (1996) How should one do the history of the self? En: Inventing our Selves, Chapter 1. London: Cambridge University Press.

Sloterdijk, P. (2012). Has de cambiar tu vida sobre antropotécnica. Valencia: Pre-texos.

Verdú, V. (2003). El estilo del mundo. La vida en el capitalismo de ficción. Barcelona: Anagrama. 


\title{
LA ENSEÑANZA Y EL APRENDIZAJE EN EDUCACIÓN FÍSICA, UN ESTADO DEL ARTE DE LA PRODUCCIÓN CIENTÍFICA EN IBEROAMÉRICA ENTRE 2005 Y 2016
}

\author{
TEACHING AND LEARNING IN PHYSICAL EDUCATION, A STATE OF THE ART OF SCIENTIFIC \\ PRODUCTION IN IBERO-AMERICA BETWEEN 2005 AND 2016
}

\author{
O ENSINO E A APRENDIZAGEM NA EDUCAÇÃO FÍSICA, UM ESTADO DA ARTE DA PRODUÇÃO \\ CIENTÍFICA EM IBERO AMÉRICA ENTRE 2005 E 2016
}

John Fredy Ariza Jiménez ${ }^{1}$
John Jairo García Díaz

\section{Resumen}

\begin{abstract}
Este artículo es resultado de una investigación que se planteó como objetivo elaborar un estado del arte sobre la producción de conocimiento científico en torno a la enseñanza/aprendizaje de la educación física en el contexto iberoamericano, entre los años 2005 y 2016. La primera parte presenta la metodología. Se realizó una búsqueda de la producción científica en diferentes bases de datos mediante frases compuestas por palabras clave; se aplicaron criterios de inclusión restringiendo la búsqueda a los idiomas español, inglés y portugués y al periodo comprendido entre los años 2005 y 2016. Los artículos científicos seleccionados se sometieron a una matriz de análisis categorial para el correspondiente proceso interpretativo. En la segunda parte, se presentan los resultados. En cuanto a las concepciones de la educación física, se evidenció principalmente una inclinación favorable hacia las tendencias sociomotricidad y actividad física y salud y algunas detracciones frente a la tendencia físico-deportiva. En lo referente a cómo se producen los procesos de enseñanza/aprendizaje, se destaca la evolución hacia los modelos constructivistas. Los hallazgos permiten evidenciar el fortalecimiento de algunas concepciones de la educación física (incluyendo la psico-motricidad y habilidades motrices básicas y la expresión corporal) que toman más fuerza en el contexto Iberoamericano, al igual que la apertura de la asignatura hacia modelos pedagógicos que brindan mayor protagonismo a los estudiantes en el proceso de enseñanza/aprendizaje.
\end{abstract}

Palabras clave: educación física; didáctica; aprendizaje; enseñanza; tendencias de la educación física; corrientes pedagógicas; modelos pedagógicos

\footnotetext{
1 Magister en Educación, especialista en Gerencia y Proyección Social de la Educación, licenciado en Educación Física. Docente investigador Corporación Universitaria CENDA. Correo electrónico: john.ariza@cenda.edu.co

2 Magister en Educación, licenciado en Educación Física. Docente investigador Corporación Universitaria CENDA. Correo electrónico: john. garcia@cenda.edu.co
} 


\section{Abstract}

This article is the result of a research aimed at elaborating a state of the art of the production of scientific knowledge about the teaching/learning of physical education in the Ibero-American context between the years 2005 and 2016. The first part presents the methodology used. A search of the scientific production in different databases was made through phrases consisting of keywords; inclusion criteria were applied, restricting the search to the Spanish, English and Portuguese languages and to the period between 2005 and 2016. The scientific articles selected were submitted to a categorical analysis matrix for the corresponding interpretative process. The second part presents the results of the research. Regarding the conceptions of physical education, we discovered a favorable inclination towards sociomotricity and physical activity and health tendencies, as well as some detraction against the physical-sportive trend. As to the teaching/learning processes, results show a particular evolution towards constructivist models. The findings are proof of the strengthening of some conceptions of physical education (including psycho-motor and basic motor skills and corporal expression) that are gaining momentum in the Ibero-American context, as well as the opening of the subject towards pedagogical models that grant greater importance for students in the teaching/learning process.

Keywords: physical education; didactics; learning; teaching; trends in physical education; pedagogical currents; pedagogical models

\section{Resumo}

Este artigo é resultado de uma pesquisa que visou elaborar um estado da arte sobre a produção de conhecimento cientifico em relação com o ensino/aprendizagem da educação física no contexto ibero-americano, entre os anos 2005 e 2016. A primeira parte apresenta a metodologia. Realizou-se uma busca da produção cientifica em diversas bases de dados por meio de frases compostas por palavras chave; aplicaram-se critérios de inclusão restringindo a busca só nas línguas espanhola, inglesa e portuguesa, e no período entre os anos 2005 e 2016. Os artigos científicos selecionados foram sometidos a uma matriz de análise categorial para o processo interpretativo. Na segunda parte, apresentam-se os resultados. Sobre as concepções da educação física, é evidente uma inclinação favorável para as tendências sociomotricidade e atividade física e saúde e algumas detrações frente à tendência físico-esportiva. Em relação com a produção dos processos de ensino/aprendizagem, assinala-se a evolução para os modelos construtivistas. As descobertas permitem evidenciar o fortalecimento de algumas concepções da educação física (incluindo a psicomotricidade, habilidades motrizes básicas e a expressão corporal) que são evidentes no contexto ibero-americano, assim como a apertura da disciplina para os modelos pedagógicos que oferecem maior participação dos estudantes no processo de ensino/aprendizagem.

Palavras chave: educação física; didática; aprendizagem; ensino; tendências na educação física; correntes pedagógicas; modelos pedagógicos

Fecha de recepción: 29 de julio de 2016

Fecha de aprobación: 3 de febrero de 2017

Para citar este artículo:

Ariza, J. y García, J. (2017). La enseñanza y el aprendizaje en Educación Física, un estado del arte de la producción científica en Iberoamérica entre 2005 y 2016. Lúdica Pedagógica, (25), 83-92. 


\section{INTRODUCCIÓN}

En la actualidad, abordar la didáctica de la educación física, convoca de manera sistemática a repensar todos los elementos que constituyen la propuesta de educar desde esta disciplina; para ello es necesario retomar los componentes del currículo, el cual, según De Zubiría (2000), "es la caracterización de los propósitos, los contenidos, la secuenciación, el método, los recursos didácticos y la evaluación. Cada uno de estos elementos resuelve una pregunta pedagógica diferente, pero interrelacionada con las demás" (p. 17).

La educación dispone de una variedad de vertientes que postulan una u otra forma como el mejor camino para concretar ese currículo y para desarrollar los procesos de enseñanza/aprendizaje; Not (1983) destaca cómo desde el siglo XVIII se han visto enfrentadas dos corrientes pedagógicas: la heteroestructurante y la autoestructurante, la primera enmarcada en el método tradicional; la segunda, se orienta hacia lo opuesto defendiendo la tesis de que el alumno mismo construye y determina su propia formación. En medio de estas dos posturas aparece la interestructuración, la cual reconoce a un estudiante activo en la producción de sus saberes, la importancia de su rol y lo trascendental del contexto (De Zubiría, 2006)

Estas corrientes pedagógicas están rodeadas y permeadas por teorías sociológicas, psicológicas (conductuales, cognitivas y constructivistas) y antropológicas que plantean un ideal de hombre y sociedad que la educación debe contribuir a formar (De Zubiría, 2000) y se plasman a través de modelos pedagógicos (Flórez, 2002).

La educación física no es ajena a esta multiplicidad de corrientes, teorías y modelos pedagógicos; el desarrollo de sus procesos de enseñanza/aprendizaje se ha visto influenciado por estas y estos desde los postulados de Mercurialis, Rousseau, Basedow, Pestalozzi, Muths, y de las escuelas gimnásticas alemana, sueca y francesa (Blázquez, 2001); hasta las tendencias actuales de la disciplina, como la físico-deportiva, la psicomotriz, la expresión corporal, la sociomotricidad, actividad física y salud, actividades en la naturaleza, y la tendencia alternativa (Zagalaz, 2001; Blázquez, 2001; Contreras 1998; Camacho, 2003); abriendo la posibilidad a un sinnúmero de opciones didácticas y a la aplicación de múltiples estilos de enseñanza (Mosston y Ashworth, 1993).
Ante este polifacético panorama pedagógico y curricular, la didáctica de la educación física, cuyo campo de estudio "está constituido por el conjunto de elementos que conforman el proceso de enseñanza/aprendizaje, así como los contextos en los que el mismo se da en referencia a las conductas motrices de relevancia educativa" (Contreras, 1998, p. 40) ha permanecido sujeto, al igual que la propia disciplina, al devenir y a los cambios impuestos por la cultura y las tendencias del momento; en este contexto de pluralidad de corrientes, teorías, modelos y apuestas pedagógicas que permean la educación física. El presente estudio estableció como objetivo elaborar un estado del arte sobre la producción de conocimiento científico en torno a la enseñanza/aprendizaje de la educación física en el contexto iberoamericano entre 2005 y 2016; para, de esta manera definir y caracterizar el contexto curricular actual de esta disciplina reconociendo sus propósitos, sus contenidos y estrategias de formación.

\section{METOdOLOgÍA}

El estudio se enmarcó en el paradigma histórico hermenéutico, se utilizó como estrategia el estado de arte y como técnica el análisis documental (Galeano, 2007); se realizó una búsqueda de artículos científicos y tesis doctorales en las bases de datos Redalyc, Scielo, Ebsco host, Proquest Education Journals y Dialnet; la citada búsqueda se centró en artículos científicos y tesis doctorales haciendo uso del descriptor booleano "AND", se utilizaron frases compuestas elaboradas de acuerdo con el tesauro de la Unesco: "Enseñanza AND Educación Física” y "Aprendizaje AND Educación Física"; la búsqueda se restringió a los idiomas español, portugués e inglés (Ensino AND educação física, aprendizagem AND educação física; Teaching AND physycal Education, Learning AND Physical education) y a la producción científica publicada entre 2005 y 2016. Para la selección final de los artículos se valoró el factor de impacto de las revistas en las que estos fueron publicados, utilizando el Scimago Journal Rank (SJR); los artículos correspondientes a revistas no indexadas allí fueron excluidos. Por último, se seleccionaron 62 artículos que se organizaron y codificaron a través de una ficha bibliográfica, la información contenida en los documentos se sistematizó en una matriz de Excel a partir de tres categorías establecidas con anterioridad: 
definición; educación física, enseña y/o aprendizaje, finalidad; proceso de enseñanza/aprendizaje de la educación física y la metodología.

\section{RESULTADOS}

\section{¿Qué es? Concepciones de la educación física (EF) y para qué. Finalidades y propósitos de sus procesos de enseñanza/aprendizaje}

Tendencia sociomotricidad

En el marco de esta tendencia, se reconoce en el uso de las prácticas corporales (capoeira) en las clases de EF una importante herramienta para rescatar manifestaciones culturales y reconocer el devenir cultural y político de su país (Brasil) (Da Costa, 2011); utilizando la EF para estudiar la cultura corporal (Rozengardt, 2005), sus aspectos históricos, sociológicos, antropológicos, pedagógicos (Romero, 2007; Cuevas, Pastor, González y Gil, 2010); psicológicos, convivenciales (Capllonch et al., citados por Capllonch y Figueras, 2012); la resolución de conflictos (Velásquez, Fraile y López, 2014; Velázquez et al., 2007; López, 2012; Sevil et al., 2015; Madrigal y Urrego, 2013; Gómez, 2005; Fernández et al., 2012; Poblete y Gamboa, 2013; López y Gea, 2010; Baena, Granero, Sánchez y Martínez, 2014 Molina y Antolin, 2008; Cárcamo, 2012); sin dejar de lado la inclusión de personas en condición de discapacidad (Robles, 2006; Fernández et al., 2012; Baena, Granero, Sánchez y Martínez, 2014 Molina y Antolín, 2008; Cárcamo, 2012).

\section{Tendencia actividad física (AF) y salud}

En cuanto a esta tendencia, se evidencia la importancia de la educación física como asignatura y disciplina que establece los lineamientos, contenidos y métodos para la AF (Reynaga, Landeros, Alonso y García, 2013), puesto que se le otorga el papel de proveedora (Gutiérrez, Ruiz y López, 2011), para la adopción de estilos de vida saludable en los jóvenes, por ser una etapa clave en la adopción y afianzamiento de hábitos. Por otro lado, se le asigna un rol fundamental al docente como facilitador o promotor de prácticas asertivas (Sevil et al., 2015; Moreno, Sicilia, Martínez y Alonso, 2008; Palao y Hernández, 2012; Baena y Granero 2015; Gutiérrez, Ruiz y López, 2011; Poblete y Gamboa, 2013; Ramírez, Mayorga y Cocca, 2014; Cuevas, García y Contreras, 2013; Monguillot, González, Guitert y Zurita, 2014; Castro, 2015; Pastor, 2007; Campos, Ries y Del Castillo, 2011).

\section{Tendencia físico-deportiva}

Según Valera, Ureña, Ruiz y Alarcón (2010) actualmente la integración del deporte como contenido curricular de la EF (Delgado, citado por Poblete y Gamboa, 2013) es muy marcada, tanto en la educación primaria, con una orientación lúdico-recreativa (Cechini, Fernández, González y Cechini, 2013; Velásquez, Fraile y López, 2014); como en la educación secundaria con más perfeccionamiento orientado hacia el desarrollo de capacidades físicas y habilidades específicas para cada deporte (Gómez et al., 2008; Lopes, 2014; Feu, Ibáñez y Gozalo, 2010). Los deportes que más se utilizan dentro de esta tendencia son los colectivos, preferiblemente los de invasión (Valera et al., 2010; Robles, Giménez y Abad, 2011; Otero, Carmona, Abornoz, Calvo y Díaz, 2014), encontrándose entre los más frecuentemente abordados, por lo menos en España, el balonmano, el baloncesto, el hockey, el fútbol y el fútbol sala.

La tendencia físico-deportiva no es muy bien aceptada por numerosos estudiosos, quienes reclaman no asignar a la EF funciones complementarias que no puede cumplir, siendo ilógico y estando demostrado que con dos horas semanales de EF no se puedan proporcionar los niveles de rendimiento que exige el deporte competitivo (Pastor, 2007). Así las cosas, López y Gea (2010) plantean que existen dos formas de entender y practicar la EF, una orientada al rendimiento y otra a la participación, situación que deriva en múltiples consecuencias a nivel curricular (contenidos, objetivos, metodologías, evaluación, etc.) que para el caso del rendimiento se inclina hacia un currículo por objetivos, con una metodología directiva que organiza el trabajo por grupos de élite motriz, y en cuya evaluación predomina la utilización de test de condición física y en pruebas de habilidades motrices y deportivas que dependen de ejecuciones técnicas determinadas.

Tendencia psicomotricidad y habilidades motrices básicas

La tendencia psicomotricidad en EF tiene sus raíces en los postulados de Le Boulch (Pastor, 2007) sobre el cuerpo, su imagen y percepción y que según Contreras (1998) se relaciona íntimamente con los bloques de contenidos del cuerpo, sus habilidades y destrezas.

Gómez, Jiménez y Sánchez (2015) resaltan en su estudio, cómo centrándose en la ejecución y organización de tareas motrices, la EF aporta al desarrollo de la autonomía y a la iniciativa personal; por su parte Madrigal y 
Urrego (2013) reconocen la relación entre el desarrollo motor y el desarrollo cognitivo afirmando que la EF contribuye desde la motricidad al desarrollo integral de los jóvenes (Velásquez, Fraile y López, 2014; Van der Kamp, Duivenvoorden, Kok y Van Hilvoorde, 2015; Cecchini, Fernández, Pallasa y Cecchini, 2012; Fernández, 2008; Gómez et al., 2008; López, 2008; Viciana, Mayorga y Cocca, 2013). Del mismo modo, Pastor (2007, citando a Le Boulch) resalta el movimiento como el principal medio de educación destacando las relaciones cuerpomovimiento acción y cuerpo-movimiento-conducta y fija (apoyado en Basquin) tres componentes dentro de la acción motriz: el esquema corporal, la representación psíquica del cuerpo y las experiencias afectivas del cuerpo; de este modo, en su estudio, Pastor (2007) anota que la EF no se puede abordar exclusivamente desde el plano motor; al intervenir es necesario tener en cuenta tanto la intención del proceso como la acción motriz para su desarrollo; en ese momento entran en juego el desarrollo psicológico, las funciones neuromotrices y las psíquicas, las capacidades mentales (análisis, síntesis, abstracción, simbolización, etc.) y lo corporal como medio para relacionarse con el mundo.

\section{Tendencia expresión corporal}

Poblete y Gamboa (2013) reconocen dentro de su estudio la teoría expresiva como una de las teorías implícitas en EF, en este contexto Gómez et al. (2008) plantean en su estudio la posibilidad de otorgarle un lugar prioritario a las situaciones expresivas de carácter comunicativo por medio del cuerpo y el movimiento del estudiante. Estas situaciones expresivas se constituyen en una opción didáctica para el desarrollo de los procesos de enseñanza/aprendizaje, considerando las necesidades particulares del género masculino y femenino (Sevil et al., 2015)

El panorama descrito evidencia la necesidad de que los docentes de EF sean competentes para el desarrollo de estas situaciones expresivas; al respecto, el estudio de Campos et al. (2011) precisa cómo trabajar la expresión corporal es la segunda competencia más valorada por los egresados maestros en EF de la Universidad de Sevilla.
¿Cómo?: se refiere particularmente a la manera como se producen o realizan los procesos de enseñanza/ aprendizaje de la Educación Física

Corriente heteroestructurante, pedagogía tradicional y conductismo en la educación física

En los documentos hallados se evidencia la corriente heteroestructurante y el modelo tradicional en las clases de EF; sobre todo en contextos donde la tendencia deportivista ocupa un lugar de preponderancia (López y Gea, 2010). Lo anterior se manifiesta en varios estudios donde se observa un débil estímulo por parte del docente en la capacidad creativa (Cárdenas, 2005, Gréhaigne y Godbout, 1997; Thorpe 1992, citados por Robles et al., 2011) y crítica del estudiante (Velásquez et al., 2007), además Robles et al. (2011) anotan que en el afán de conseguir la asimilación de gestos técnicos, la metodología tradicional es una constante, con actividades repetitivas y descontextualizadas (Valera et al., 2010; Calderón, Martínez y Hastie, 2013).

\section{Corriente autoestructurante y escuela}

activa en la educación física

Gómez et al. (2015) sostiene que las intervenciones docentes que promueven la autonomía (Baena y Granero, 2015) y la toma de decisiones obtienen mejores resultados en el desarrollo de habilidades motoras, práctica de actividad física, reducción de la desmotivación y del aburrimiento, aumento en los niveles de satisfacción, responsabilidad y aprendizaje adquirido (Hastie, Rudisill, y Wadsworth; Moreno, Parra y González-Cutre; Méndez, Cecchini, Fernández y González; Calderón, Martínez y Hastie; Gordon; Llopis et al.; Pascual et al.; Calderón, Martínez y Martínez; Lorente; citados por Gómez, Jiménez y Sánchez, 2015).

En ese mismo sentido trabajos como los de Gutiérrez et al. (2011), y Ruiz y Piéron (2013) ratifican la importancia de la orientación hacia metas de maestría (orientadas hacia la tarea) las cuales mejoran los niveles de motivación y autodeterminación puesto que los sujetos juzgan su nivel de capacidad a partir de un proceso de comparación con ellos mismos, mientras que cuando la meta es de competitividad, los individuos juzgan si son o no competentes, comparándose con los demás (Cervelló, Escartí y Balagué; Nicholls; Roberts y Treasure; citados por Ruiz y Piéron, 2013, p. 237). 
Corriente interestructurante y modelos

constructivistas en la educación física

Calderón, Martínez y Hastie (2013) afirman que los modelos de enseñanza aplicados en la EF han evolucionado de una tendencia magiocentrista a una que le da más valor al estudiante, que lo insta a la resolución de problemas, a la toma de decisiones y que promueve su autonomía. En ese contexto aparecen diferentes modelos entre los que los mismos autores destaca la educación deportiva y la enseñanza comprensiva de los deportes (Velázquez et al., 2007; Abad, Benito, Giménez y Robles, 2013; González, Gil, Contreras y Pastor, 2008; Alarcón et al., 2011; Robles, Giménez y Abad, 2011; Clemente, 2014; Castro, 2015; Vera, 2010), aprendizaje cooperativo (López, 2012; Velázquez, Fraile y López, 2014; Capllonch y Figueras, 2012; López, 2008), centrado en valores y crítico (López, 2012; López y Gea, 2010).

Estas corrientes interestructurantes y modelos constructivistas abren la posibilidad a la aplicación del juego en las clases de EF y de la mano de este a la creatividad, tal y como se evidencia en los estudios de Valero (2006), Rozengardt (2005) y Cechini et al. (2012); además promueven oportunidades de trabajo interdisciplinar, enfoques de aprendizaje integrado y propuestas de aprendizaje servicio (Del Valle, De la Vega y Rodríguez, 2015; Granero y Baena, 2015; Fernández, 2008; Coral y Lleixà, 2014; Martínez de Ojeda, Calderón y Campos, 2012; Corbatón et al., 2015); resaltándose también una presencia importante de metodologías fundamentadas en la orientación hacia la tarea y las metas de logro (Gómez, Jiménez y Sánchez, 2015; Cuevas et al., 2010; Navas, Soriano y Holgado, 2006; Cuevas, García y Contreras, 2013; Baena, Granero, Gómez y Abraldes, 2014; Moreno, Vera y Cervello, 2009). En esa misma línea, estudios como los de Baena et al. (2014); Palao y Hernández (2012); Sevil et al. (2015); Cea, Véliz, Aravena y Maureira (2014); Cechini et al. (2013); Vera, Moreno y Moreno (2009), y Gutiérrez y López (2011) evidencian los beneficios de teorías como la de la autodeterminación, las necesidades básicas y la cesión de responsabilidad.

\section{CONCLUSIONES}

Los hallazgos del presente estudio permiten evidenciar que tendencias de la EF como sociomotricidad, actividad física y salud toman fuerza exponiéndolas como las más adecuadas ante las limitaciones y desorientaciones de tendencias como la físico-deportiva y la de expresión corporal; la fuerte presencia de estas tendencias en la producción científica pone sobre la mesa concepciones que tienen más prioridad en el aspecto humano que en el técnico, que reconocen el cuerpo y el movimiento como actores indispensables en procesos de comunicación, interacción y transformación social.

Se muestra el modelo constructivista e interestructurante en EF como una posibilidad didáctica que está sobresaliendo y dejando atrás las corrientes heteroestructurantes, relegándolas prácticamente a una instrucción técnica fuera de contexto y realidad de juego en el marco de la tendencia deportivista. En detrimento de esas metodologías jerarquizadas y autoritarias, se observa el surgimiento de propuestas en torno a un rol del maestro como mediador y a favor del aprendizaje cooperativo y dialógico, del incremento de la motivación mediante la autodeterminación y las metas orientadas a la tarea y no al ego; una EF cuyos procesos de enseñanza/ aprendizaje parten de la cesión de responsabilidad, los valores, el pensamiento crítico, las habilidades interpersonales y el trabajo interdisciplinar, todo esto con influencia en lo cognitivo, lo social y lo afectivo.

\section{REFERENCIAS}

Abad, M., Benito, P., Giménez, F. y Robles, J. (2013). Fundamentos pedagógicos de la enseñanza comprensiva del deporte: Una revisión de la literatura. Cultura, Ciencia y Deporte, 8(23), 137-146.

Alarcón, L., Cárdenas, V., Piñar, M., Miranda, M. y Ureña, 0. (2011). La concepción constructivista como modelo explicativo del aprendizaje en los deportes de equipo. Universitas Psychologica, 10(2), 489-500.

Baena, A. y Granero, A. (2015). Educación física e intención de práctica física en tiempo libre. Revista Electrónica de Investigación Educativa, 17(3), 132-144.

Baena, A., Granero, A., Gómez, M. y Abraldes, J. (2014). Orientaciones de meta y clima motivacional según sexo y edad en educación física. Cultura, Ciencia y Deporte, 9(26), 119-128.

Baena, A., Granero, A., Sánchez, J. y Martínez, M. (2014). Modelo predictivo de la importancia y utilidad de la Educación Física. Cuadernos de Psicología del Deporte, 14(2), 121-130.

Blázquez, D. (2001). La educación física. Barcelona, España: INDE Publicaciones. 
Calderón, A., Martínez, D. y Hastie, P. (2013). Valoración de alumnado y profesorado de educación física tras la aplicación de dos modelos de enseñanza. RICYDE. Rev. Int. Cienc. Deporte., 32(9), 137-153.

Camacho, H. (2003). Pedagogía y didáctica de la educación física. Armenia, Colombia: Editorial Kinesis.

Campos, M., Ries, F. y Del Castillo, O. (2011). Análisis de las competencias adquiridas y utilizadas por los egresados maestros en Educación Física. International Journal of Sport Science, 7(24), 216-229.

Capllonch, M. y Figueras, S. (2012). Educación física y comunidades de aprendizaje. Estudios Pedagógicos, 38, 231-247.

Cárcamo, J. (2012). El profesor de educación física desde la perspectiva de los escolares. Estudios Pedagógicos, 38(1), 105-119.

Castro, S. (2015). Aprendizaje dialógico y educación física: Hacia una educación física y un deporte escolar promotores de salud, éxito escolar y cohesión social. Intangible Capital, 11(3), 393-417.

Cea, S., Véliz, C., Aravena, C. y Maureira, F. (2014). Percepción de los estudiantes de educación física de la UISEK de Chile hacia sus profesores. Cuadernos de Psicología del Deporte, 14(1), 23-28.

Cecchini, J., Fernández, J., González, C. y Cechini, C. (2013). Aplicaciones del modelo de autodeterminación en la educación física de primaria. Revista Latinoamericana de Psicologia, 45(1) 97-109.

Cecchini, J.A., Fernández, J.L., Pallasa, M. y Cecchini, C. (2012). El proceso de transferencia en el aprendizaje y desarrollo motor. Psicothema, 24(2), 205-210.

Clemente, M. (2014). Uma Visão Integrada do Modelo Teaching Games for Understanding: Adequando os Estilos de Ensino e Questionamento à Realidade da Educação Física. Revista Brasileira de Ciências do Esporte, 36(2) 587-601.

Contreras, J. (1998). Didáctica de la educación física. Barcelona, España: INDE Publicaciones.

Coral, J. y Lleixà, T. (2014). La enseñanza de la educación física mediante el enfoque educativo Clil: la resolución de los dilemas profesionales surgidos durante un proceso de investigación-acción. Movimento, 20(4), 1447-1472.

Corbatón, R., Moliner, M., Martí, M., Gil, J. y Chiva, 0. (2015). Efectos académicos, culturales, participativos y de identidad del aprendizaje-servicio en futuros maestros a través de la educación física. Profesorado, Revista de Currículum y Formación de Profesorado, 19(1), 280-297.
Cuevas, R., García, T. y Contreras, O. (2013). Perfiles motivacionales en educación física: una aproximación desde la teoría de las metas de logro $2 \times 2$. Anales de Psicología, 29(3), 685-69.

Cuevas, R., Pastor, J., González S. y Gil, P. (2010). Educación física intercultural, motivación y prejuicio racial: una aproximación desde la teoría de las metas de logro. Cuadernos de Psicología del Deporte, 10(Suple), 37-42.

Da Costa, P. (2011). Capoeira nas aulas de educação física: alguns apontamentos sobre processos de ensinoaprendizado de professores. Rev. Bras. Ciênc. Esporte, florianópolis, 33(4), 889-903.

De Zubiría, J. (2000). Los modelos pedagógicos. Tratado de pedagogía conceptual. Bogotá: Fundación Alberto Merani para el Desarrollo de la Inteligencia Cooperativa.

De Zubiría, J. (2006). Los modelos pedagógicos. Hacia una pedagogía dialogante. Bogotá: Cooperativa Editorial Magisterio.

Del Valle, S., De la Vega, R. y Rodríguez, M. (2015). Percepción de las competencias profesionales del docente de educación física en primaria y secundaria. Revista Internacional de Medicina y Ciencias de la Actividad Física del Deporte, 15(59), 507-526.

Fernández Abuín, J.P. (2008). El movimiento olímpico y las nuevas tecnologías en el área de Educación Física y Deporte a través del modelo didáctico de la webquest. Revista Internacional de Medicina y Ciencias de la Actividad Física y el Deporte, 8(29), 1-14.

Fernández, J.P. (2008). El movimiento olímpico y las nuevas tecnologías en el área de educación física y deporte a través del modelo didáctico de la webquest. Revista Internacional de Medicina y Ciencias de la Actividad Física y el Deporte, 8(29), 1-14.

Fernández, M., Sánchez, C., Jiménez, F., Navarro, V. y Anguera, M. (2012). Sistema de codificación y análisis de la calidad del dato para una intervención inclusiva en educación física. Revista de Psicología del Deporte, 21(1), 67-73.

Fernández, M., Sánchez, C.R., Jiménez, F., Navarro, V. y Anguera, M. (2012). Sistema de codificación y análisis de la calidad del dato para una intervención inclusiva en educación física. Revista de Psicología del Deporte, 21(1), 67-73.

Feu, S., Ibáñez, S. y Gozalo, M. (2010). La formación inicial de los entrenadores de balonmano para la enseñanza del deporte en la edad escolar. Cultura, Ciencia y Deporte, 5(14), 109-117.

Flórez, R. (2000). Hacia una pedagogía del conocimiento. Bogotá: McGraw-Hill. 
Flórez, R. (2002). Modelos pedagógicos y enseñabilidad de las ciencias. Actualidades Pedagógicas, 42, 17-26.

Galeano, M. (2007). Estrategias de investigación Social Cualitativa. El giro de la mirada. Medellín, Colombia: La Carreta Editorial.

Gómez, A. (2005). La enseñanza y el aprendizaje de los valores en la educación Deportiva. Revista Internacional de Medicina y Ciencias de la Actividad Física y el Deporte, 5(18), 89-99.

Gómez, A., Jiménez, F. y Sánchez, C. (2015). Desarrollo de la autonomía del alumnado de primaria en educación física a través de un proceso de investigación-acción. RICYDE. Revista Internacional de Ciencias del Deporte, 11(42), 310-328.

Gómez, A., Díez, L.J., Fernández, J.M., Gorrín, A., Pacheco, J.J. y Sosa A., G. (2008). Nueva propuesta curricular para el área de Educación Física en la Educación Primaria. Revista Internacional de Medicina y Ciencias de la Actividad Física y el Deporte, 8(29), 93-108.

González, S., Gil, P., Contreras, 0. y Pastor, J. (2008). Propuesta de formación permanente del profesorado de educación física sobre deportes de invasión. Perfiles educativos, 30(121), 7-124.

Granero, A. y Baena, A. (2015). Diseños de aprendizaje basados en las TIC (Moodle 2.0 y Mahara) para contenidos de Anatomía, Fisiología y Salud en las clases de Educación Física escolar. International Journal of Morphology, 33(1), 375-381.

Gutiérrez, M. y López, E. (2011). Percepción de las estrategias que emplean los profesores para mantener la disciplina, razones de los alumnos para ser disciplinados y comportamiento en educación física. International Journal of Sport Science, 7(22), 24-38.

Gutiérrez, M., Ruiz, L. y López, E. (2011). Clima motivacional en educación física: concordancia entre las percepciones de los alumnos y las de sus profesores. Revista de Psicología del Deporte Universität de les liles Balears, 20(2), 321-335.

Lopes, E. (2014). Quando "rola a bola": reflexões sobre as práticas futebolísticas e a forma escolar nas aulas de educação física. Rev. Bras. Ciênc. Esporte, florianópolis, 36(2), 501-513.

López, V.M. (2012). Didáctica de la educación física, desigualdad y transformación social. Estudios Pedagógi$\cos , 38(1), 155-176$.

López, V.M. (enero-abril de 2008). La importancia del trabajo colaborativo para el tratamiento de la motricidad infantil. Una propuesta integral a partir del aprendizaje inducido. Revista Española de Pedagogía, $239,137-150$.
López, V.M. y Gea, J.M. (2010). Innovación, discurso y racionalidad en Educación Física. Revisión y prospectiva. Revista Internacional de Medicina y Ciencias de la Actividad Física y el Deporte, 10(38), 245-270.

Madrigal, A. y Urrego, A. (2013). La educación física renovada desde la investigación educativa. Revista Lasallista de Investigación, 10(2), 69-76.

Martínez de Ojeda, D., Calderón, A. y Campos, A. (2012). Percepción de aprendizaje y satisfacción en una unidad didáctica integrada mediante el modelo de educación deportiva. Cultura, ciencia y deporte, 7(21) 163-172.

Molina, J. y Antolín, l. (2008). Las competencias básicas en educación física: una valoración crítica. Cultura, Ciencia y Deporte, 3(8), 81-86.

Monguillot, M., González, C., Guitert, M. y Zurita, C. (2014). Mobile learning: a collaborative experience using QR codes. Mobile Learning Applications in Higher Education [Special Section]. Revista de Universidad y Sociedad del Conocimiento, 11(1) 175-191.

Moreno, J., Sicilia, A., Martínez, C. y Alonso, N. (2008). Coeducación y climas de aprendizaje en educación física. Aportaciones desde la teoría de metas de logro. Revista Internacional de Ciencias del Deporte, 11(4), 42-64.

Moreno, J.A., Vera, J.A. y Cervello, E. (2009). Efectos de la cesión de responsabilidad de la evaluación en la motivación y la competencia percibida en el aula de educación física. Revista de Educación, 348, 423-440.

Mosston, M. y Ashworth, S. (1993). La enseñanza de la educación física. la reforma de los estilos de enseñanza. Barcelona, España: Editorial Hispano-Europea.

Navas, L., Soriano, J.A. y Holgado, F.P. (2006). Orientaciones de meta en las clases de educación física: un análisis centrado en la educación secundaria obligatoria. Revista de Psicología del Deporte, 15(2), 167-181.

Not, L. (1983). Las pedagogías del conocimiento. México D.F.: Fondo de Cultura Económica.

Ortiz, A. (2011). Hacia una nueva clasificación de los modelos pedagógicos: el pensamiento configuracional como paradigma científico y educativo del siglo XXI. Revista Praxis, 7, 121-137.

Otero, F.M., Carmona, J., Albornoz, M., Calvo, A. y Díaz, J.A. (2014). Metodología de enseñanza de los deportes de invasión en primaria. Revista Internacional de Medicina y Ciencias de la Actividad Física y el Deporte, 14(53), 69-87.

Palao, J. y Hernández, E. (2012). Validación de un instrumento para valorar la percepción del aprendizaje y el nivel de diversión del alumno en educación física. El semáforo. Cuadernos de Psicología del Deporte, 12(1), 25-32. 
Pastor, J.L. (2007). Fundamentación epistemológica e identidad de la educación física. Profesorado. Revista de currículum y formación del profesorado, 11(2),1-17.

Poblete, C. y Gamboa, R. (2013). Teorías implícitas y proyectos educativos: una visión paradigmática de la educación física. Educere, 17(58), 465-474.

Ramírez, J., Mayorga, D. y Cocca, A. (2014). Modelo de aprendizaje exitoso en educación física y su mantenimiento. Estudio del efecto del refuerzo intermitente sobre la condición física Facultad de Ciencias de la Actividad Física y el Deporte. Revista Iberoamericana de Psicología del Ejercicio y el Deporte, 9(1),155-171.

Reynaga, P., Landeros, A., Alonso, T. y García, A. (2013). Presencia curricular de la psicología de la actividad física y del deporte en los planes de estudio de pregrado y posgrado de educación física versus psicología, en México. Revista Brasileira de Ciências do Esporte, 35(4) 847-863.

Robles, J. (2006). Judo para ciegos como contenido novedoso en las clases de educación física. Unidad Didáctica. Revista Internacional de Medicina y Ciencias de la Actividad Física y el Deporte, 6(22), 75-86.

Robles, J., Giménez, F.J. y Abad, M.T. (2011). Metodología utilizada en la enseñanza de los contenidos deportivos durante la E.S.O. Revista Internacional de Medicina y Ciencias de la Actividad Física y el Deporte, 11(41), 35-57.

Romero, C. (2007). Delimitación del campo didáctico de la educación física y de su actividad científica. Profesorado. Revista de Currículum y Formación del Profesorado, 11(2), 1-45.

Rozengardt, R. (2005). Aprendizaje, juego y niño: un modo de entender la educación física. Revista Brasileira de Ciências do Esporte, 26(3) 111-126.

Ruiz, J.F. y Piéron, M. (2013). Orientaciones de meta en Educación Física y nivel de actividad físico-deportiva en estudiantes mexicanos. Universitas Psychologica, 12(1), 235-247.

Sevil, J., Abós, A., Julian, J.A., Murillo, B. y García-González, L. (2015). Género y motivación situacional en educación física: claves para el desarrollo de estrategias de intervención. RICYDE. Revista Internacional de Ciencias del Deporte, 41(11), 281-296.
Valera, S., Ureña, N., Ruiz, E. y Alarcón, F. (2010). La enseñanza de los deportes colectivos en Educación Física en la E.S.O. Revista Internacional de Medicina y Ciencias de la Actividad Física y el Deporte, 10(40), 502-520.

Valero, A. (2006). La evaluación en el modelo de enseñanza ludotécnico para la iniciación a la práctica del atletismo dentro del contexto escolar. Cultura, ciencia y deporte, 2(5) 89-94.

Van der Kamp, J., Duivenvoorden, J., Kok, M. y Van Hilvoorde, I. (2015). Aprendizaje de habilidades/ destrezas motoras en grupos: propuestas para la aplicación de aprendizaje implícito, autocontrolado y retroalimentado. RICYDE. Revista Internacional de Ciencias del Deporte, 39(11), 33-47.

Velázquez, C., Fraile, A. y López, V. (2014). Aprendizaje cooperativo en educación física. Movimento, 20(1), 239-259.

Velázquez, R., Hernández, J., Garoz, I., López, C., López, M., Maldonado, A., Martínez, M., Villagra, A. y Castejón, J. (2007). Calidad de enseñanza en educación física y deportiva y discurso docente: el caso de la comunidad de Madrid. Revista de Educación, 344, 447-467.

Vera, J. (2010). Autobiografía, identidad docente y conocimiento didáctico en la enseñanza de la educación física. Revista Complutense de Educación, 21(2), 423-44.

Vera, J.A., Moreno, R. y Moreno, J. (2009). Relaciones entre la cesión de responsabilidad en la evaluación y la percepción de igualdad en la enseñanza de la educación física escolar. Cultura, Ciencia y Deporte, 4(10), 25-31.

Viciana, J., Mayorga, D. y Cocca, A. (2013). Modelo de aprendizaje exitoso en educación física y su mantenimiento. Estudio del efecto del refuerzo intermitente sobre la condición física. Revista Iberoamericana de Psicología del Ejercicio y el Deporte, 9(1), 155-171.

Zagalaz, L. (2001). Corrientes y tendencias de la educación física. Barcelona, España: INDE Publicaciones. 